\title{
Anti-apoptotic and antioxidant effects of melatonin protect spleen of whole body $\gamma$-irradiated male Sprague-dawley rats
}

\author{
A. Farid ${ }^{*}$, M. El-Dewak ${ }^{2}$, G. Safwat ${ }^{2}$, A. Diab ${ }^{2}$ \\ ${ }^{1}$ Zoology Department, Faculty of Science, Cairo University, Cairo, Egypt \\ ${ }^{2}$ Faculty of Biotechnology, October University for Modern Sciences and Arts (MSA), Cairo, Egypt
}

\section{- Original article}

\author{
*Corresponding author: \\ Alyaa Farid, Ph.D., \\ E-mail: \\ alyaafarid@yahoo.com
}

Revised: January 2021

Accepted: February 2021

Int. J. Radiat. Res., October 2021; 19(4): $861-872$

DOI: $10.29242 /$ ijrr.19.4.861

\begin{abstract}
Background: Spleen is the largest lymphatic organ that is seriously affected during irradiation. Radiation exposure reduces both of spleen size and weight; that in turn decreases the numbers of immune cells. Melatonin is an effective free radicals scavenger. Therefore, this study aimed to evaluate the effects of melatonin on both blood and spleen of whole body $\gamma$-irradiated male Sprague dawley rats. Materials and methods: Animals were intraperitoneally injected with $100 \mathrm{mg} / \mathrm{kg}$ melatonin prior to radiation exposure by 30 minutes. Experimental groups were group I: control rats, group II: irradiated rats, group III: melatonin administrated unirradiated rats and group IV: melatonin administrated irradiated rats. Blood and spleen samples were collected 24 hours post irradiation for biochemical, immunological and blastogenesis measurements. Apoptosis, pro- and anti-apoptotic proteins of spleen cells were measured by flow cytometry techniques. Results: Melatonin significantly upregulated the activities of superoxide dismutase (SOD), glutathione (GSH) and catalase (CAT); and reduced malondialdehyde (MDA). It down regulated the expression of pro-apoptotic proteins (p53, Bax, caspase -3 and caspase-8) and up regulated the expression of anti-apoptotic protein $\mathrm{Bcl}-2$ in spleen cells; that in turn reduced the radiation-induced apoptosis. Levels of pro-inflammatory cytokines (TNF- $\alpha$, IFN- $\gamma$ and IL-1 $\beta$ ) were significantly reduced in group IV. Blastogenesis assay showed that melatonin protects PBMC and spleen B lymphocytes and stabilized their proliferation. Conclusion: Melatonin administration prior to whole body $\mathrm{v}$-radiation successfully protected rat's spleen from the consequences of radiation exposure. This was due to its free radicle scavenger nature, its reduction of lipid peroxidation and its anti-apoptotic effects.
\end{abstract}

Keywords: y-radiation, melatonin, apoptosis, P53, BCl-2.

\section{INTRODUCTION}

For long time, radiotherapy has been used in cancer treatment for removing tumors, preventing cancer recurrence, reduction of physical pain and prolongs life (1). However, radiotherapy is not restricted to cancer cells only; as it has several acute and chronic side effects such as fibrosis, bowel destruction, bleeding, diarrhea and the appearance of secondary cancers ${ }^{2}$ ). Ionizing radiation reacts with water molecules inside the cells leading to the formation of free radicles such as reactive oxygen species (ROS) and reactive nitrogen species (RNS) (3). These free radicles have the ability to attack cellular DNA and other organelles inside the cells. Many studies confirmed that irradiation can trigger cell death through several mechanisms such as apoptosis, necrosis and autophagy (4). Moreover, as the dose of irradiation increases, damaged cells releases danger alarms that will be recognized 
by lymphocytes and macrophages (5). All these processes are responsible for the production of ROS and several cytokines such as: IL-6, IL-4, TNF- $\alpha$, IFN- $\gamma$, IL- $1 \beta$ and others ( 6 ). This massive progressive inflammation leads to the reduction of the antioxidant defense system inside the cells, an increase in oxidative stress, DNA fragmentation and cell death (7).

The reticuloendothelial system consists of blood monocytes, connective tissues macrophages, liver, lung, bone marrow and lymphoid organs especially spleen. It is responsible for the removal of immune complexes from the circulation. Spleen is considered the largest reticuloendothelial organ that is composed of lymphoid tissues and vessels (8). It is responsible for the filtration of abnormal red blood cells, inclusion bodies and foreign particles as it regulates both humoral and cellular immune response; and contributes to the body defense mechanisms. In addition, it has a significant role in the deposition of circulating blood cells and platelets, hematopoiesis, hemoglobin degradation, iron recycling and plasma volume regulation ${ }^{(9)}$. During whole body irradiation, all body tissues especially spleen will be affected. Irradiation causes a reduction in the spleen size and weight; and eventually a significant decrease in the numbers of immune cells (10).

$\mathrm{N}$-acetyl-5-methoxytryptamine, known as melatonin, is an endogenous compound secreted by the pineal gland in the brain. Melatonin regulates several physiological mechanisms, pathological conditions (11) and circadian rhythms of diurnal organisms (12). It is characterized by half-life time of 30 to 57 minutes in serum (13), small size and high lipophilicity. These properties enable melatonin to cross biological membranes and reach all cells' compartments (14). Upon its synthesis in pineal gland, it is released into the blood stream then into other fluids of the body (15). Therefore, melatonin can protect various body organs against different side effects of radiation because of the ease with which it penetrates all types of cells in the body (16). It has been reported, by many studies, that melatonin is a potent free radical scavenger and has an antioxidant effect
(17-18); as it stimulates the antioxidant enzymes' activities such as catalase (CAT) and superoxide dismutase (SOD) (19). Melatonin has radioprotective properties as it reduced radiation-induced apoptosis in retinal cells (20), bone marrow (21), mice thymocytes (22) and rat neurons (23). It is a powerful antioxidant and anti -inflammatory agent, which shows some anticancer effects. It is able to reduce different types of free radicals and pro-oxidant enzymes that were stimulated after radiation exposure and played a significant role in normal tissue protection (24). Melatonin saved hematopoiesis during chemotherapy of Lewis lung carcinoma-bearing mice (22). Vijayalaxmi et al. (25) observed that human peripheral blood mononuclear cells (PBMC) pretreated with melatonin in-vitro prior to $\gamma$-radiation showed a significant decrease in the occurrence of micronuclei and chromosomal aberrations. Anwar et al. (26) showed that melatonin protected bone marrow and lymphoid tissues in rats exposed to cytotoxic drugs. Canyilmaz et al. (27) reported that melatonin supplementation before irradiation protected mice against radiation-induced nephrotoxicity. Kamal El-Dein and Anees (28) have reported that the ameliorative effect of melatonin against $\gamma$-irradiation induced testicular damage was a result of its antioxidant properties. Also, Seker et al. (29) examined the protective effects of melatonin, amifostine (WR-2721), and $\mathrm{N}$-acetylcysteine on radiotherapy-induced uterine tissue injury in rats. They found that melatonin was the most successful one and can be an alternative to amifostine.

However, a successful radioprotector would selectively protect normal cells without adverse effects on tumor response (30). Furthermore, a good radiosensitizer should not elevate the toxicity of normal cells. Several studies, in recent years, have showed that melatonin has radiosensitizer effects on tumor cells in addition to its radioprotective effects. These dual natures of melatonin make it a good candidate for radiotherapy. Samei et al. (31) reported the radioprotective effects of melatonin in addition to its anticancer effects; and their results showed that melatonin led to an elevated level of 
radiation induced chromosomal aberrations in lymphocytes from breast cancer patients. Also, Alonso -Gonzalez et al. (32) showed that pretreatment of breast cancer cells with melatonin led to cell sensitization to ionizing radiation by the down regulation of proteins involved in the breakdown of DNA.

In view of the previous facts and because of the controversies over the role of melatonin during radiation exposure, the present study aimed to evaluate the effects of melatonin on both blood and spleen of whole body $\gamma$-irradiated male Sprague dawley rats. This was accomplished by administrating rats with 100 $\mathrm{mg} / \mathrm{kg}$ of melatonin 30 minutes prior to radiation exposure. Blood and spleen samples were collected for biochemical, immunological and blastogenesis measurements. Apoptosis, pro -apoptotic proteins (p53, Bax, caspase-3 and caspase-8) and the anti-apoptotic protein Bcl-2 in spleen cells were measured by flow cytometry techniques.

\section{MATERIALS AND METHODS}

\section{Chemicals}

Melatonin (Sigma-Aldrich, St. Louis, MO, USA) was dissolved in ethanol (Al-Gomhoria Company for medicines and medical supplies, Egypt) to reach $1 \%$ concentration then diluted in $0.9 \%$ sodium chloride (Al-Gomhoria Company for medicines and medical supplies, Egypt). Animals received intraperitoneal injection of $100 \mathrm{mg} / \mathrm{kg}$ melatonin 30 minutes before radiation exposure.

\section{Experimental animals}

Forty male Sprague-Dawley rats of age 16 weeks $(180 \pm 20 \mathrm{~g})$ were purchased from Theodor Bilharz Research Institute; and randomly divided into 4 groups (10 rats each). Group I: control unirradiated rats receiving 0.9\% sodium chloride only, group II: irradiated rats receiving $0.9 \%$ sodium chloride only, group III: unirradiated rats receiving $100 \mathrm{mg} / \mathrm{kg}$ melatonin and group IV: irradiated rats receiving $100 \mathrm{mg} / \mathrm{kg}$ melatonin. The animals were allowed to acclimatize for two week before the start of the experiment. Animal handling, Int. J. Radiat. Res., Vol. 19 No. 4, October 2021 care and all experimental procedures were done according to the international care and use of laboratory animals' guidelines. Animals were kept in plastic cages with stainless-steel grid tops under controlled temperature $\left(22 \pm 2^{\circ} \mathrm{C}\right)$ and on $12 / 12$ hour dark/light cycle with standard diet containing all nutritive elements (proteins, fats, carbohydrates, vitamins, salts and minerals) and water ad libitum. Experimental protocols used in this study were approved by the ethics Committee of Cairo University, Egypt on October 2019.

\section{Irradiation protocol}

Animals were subjected to whole body $\gamma$-radiation using a Gamma Cell-40 Carloirradiator, ${ }^{137} \mathrm{Cs}$ source. Rats were irradiated at an acute single dose level of $6 \mathrm{~Gy}$ that was delivered at a dose rate of $0.713 \mathrm{cGy} /$ sec. Animals were starved for 12 hours before radiation exposure and were anesthetized by a combination of Ketamine $50 \mathrm{mg} / \mathrm{kg}$, Xylazine 5 $\mathrm{mg} / \mathrm{kg}$ and Thiopental sodium $50 \mathrm{mg} / \mathrm{kg}$ (Sigma-Aldrich, St. Louis, MO, USA).

\section{Samples preparation}

At the end of experiment, 24 hours post irradiation; animals were anesthetized with pentobarbital (80 mg/kg) (33). Blood samples were collected by cardiac puncture in heparinized tubes and centrifuged at $500 \mathrm{~g}$ for 10 minutes. Plasma samples were separated and kept at $-80^{\circ} \mathrm{C}$. Spleen samples were homogenized in cold Tris-HCl buffer $(0.1 \mathrm{M}, \mathrm{pH}$ 7.4, Sigma-Aldrich, USA) for preparation of $10 \%$ homogenate followed by centrifugation at $4^{\circ} \mathrm{C}$. The supernatant was used for biochemical and immunological measurements of the spleen.

\section{Blood analysis}

Number of red blood cells, white blood cells, platelets and hemoglobin level were determined in $2 \mathrm{ml}$ of heparinized blood samples using an automatic counter (Labcompare, USA).

\section{Biochemical analysis of spleen samples}

Malondialdehyde (MDA) was measured by lipid peroxidation (MDA) assay kit (RTEB1739, ELISA Genie, Ireland). The antioxidant levels 
were measured through determining the activities of superoxide dismutase (SOD, MBS036924, MyBioSource, USA), catalase (CAT, EKU03009, Biomatik, USA) and glutathione (GSH, RTEB1811, ELISA Genie, Ireland).

\section{Flow cytometry technique}

Apoptosis was evaluated in spleen samples using annexin-V-FITC/PI apoptosis detection kit (ab14085, abcam, USA) according to the manufacturer's instructions. For measuring intracellular proteins, rat spleen tissue samples were disaggregated using a syringe and stainless sieves, filtered and centrifuged. Cells were fixed in $2 \%$ paraformaldehyde (Sigma-Aldrich, USA) then permeabilized by saponin $(0.5 \% \mathrm{v} / \mathrm{v}$ in PBS, pH 7.4; Sigma-Aldrich, USA). Spleen cells were suspended in PBS/BSA (2\%), divided into aliquots and stored at $4{ }^{\circ} \mathrm{C}$ for flow cytometric analyses. Also, pro-apoptotic proteins p53, Bax, caspase- 3 and caspase- 8 and the anti-apoptotic protein Bcl-2 were determined using anti-p53 antibody [pAb122] (ab90363, ABCAM, USA), Bax monoclonal antibody (6A7) (MA5-14003, Thermo Fisher Scientific, USA), FITC anti- active caspase-3 (Clone C92-605, RUO, 559341, BD Biosciences, USA), anti-caspase-8 antibody [E6] (ab32125, ABCAM, USA) and FITC Bcl-2 monoclonal antibody (10C4, 11-6992-42, Thermo Fisher Scientific, USA), respectively.

\section{Cytokines measurements}

Levels of pro-inflammatory cytokines (TNF- $\alpha$, IFN- $\gamma$ and IL-1 $\beta$ ) were measured in plasma and spleen tissue homogenate supernatants using rat TNF- $\alpha$ (ab46070, ABCAM, USA), IFN- $\gamma$ (ERIFNG, Invitrogen Thermo Fisher Scientific, USA) and IL-1 $\beta$ (BMS630, Invitrogen Thermo Fisher Scientific, USA) ELISA kits, respectively, according to the manufacturer's instructions.

\section{Spontaneous PBMC blastogenesis measurements}

PBMC were separated from heparinized blood samples from all experimental groups by Ficoll-hypaque gradient separation and suspended in culture medium [RPMI1640 supplemented with $10 \%$ heat-inactivated human serum, $50 \mathrm{U} / \mathrm{ml}$ penicillin, $50 \mathrm{mg} / \mathrm{ml}$ streptomycin and $2 \mathrm{mM}$ L-glutamine (Sigma Aldrich, USA)]. Triplicate cultures of $2 \times 10^{6}$ cells in $200 \mu \mathrm{l} /$ well were dispensed into round-bottomed microtiter plates. $50 \mu \mathrm{l}$, containing $1 \mu \mathrm{Ci}$, tritiated thymidine $\left({ }^{3} \mathrm{H}-\mathrm{TdR}\right.$, Sigma Aldrich, USA) (specific activity $2 \mathrm{Ci} / \mathrm{mM}$ ) were added to each well, and the plates were incubated for 3 hours at $37^{\circ} \mathrm{C}$ in humid atmosphere containing $5 \% \quad \mathrm{CO}_{2}$. Cells were harvested using automated harvester (Inotech Cell Harvester, USA) and the incorporated radioactivity was determined by a scintillation counter (Beckman, USA).

\section{Spontaneous and mitogen-induced blastogenesis of spleen lymphocytes:}

$2 \times 10^{6} / \mathrm{ml}$ of viable carefully washed spleen lymphocytes were suspended in RPMI 1640 medium (10\% heat-inactivated human serum and $50 \mu \mathrm{g} / \mathrm{ml}$ gentamicin). One-tenth milliliter of spleen lymphocytes were dispensed into microtiter plate with phytohaemagglutinin (PHA), concanavalin A (Con A), lipopolysaccharides (LPS) or no mitogen. Plates were incubated for 72 hours at $37^{\circ} \mathrm{C}$ in humid atmosphere containing $5 \% \mathrm{CO}_{2}$. $50 \mu \mathrm{l}$, containing $1 \mu \mathrm{Ci}$, of ${ }^{3} \mathrm{H}-\mathrm{TdR}$ (Sigma Aldrich, USA) were added to each well and the plates were incubated for 24 hour. Cells were harvested using automated sample harvester (Inotech Cell Harvester, USA) and the incorporated radioactivity was determined by a scintillation counter (Beckman, USA). Stimulation index was calculated from: (dpm with mitogen - dpm without mitogen)/dpm without mitogen, dpm: disintegration per minute.

\section{Statistical analysis}

Statistical analyses were accomplished using SPSS version 13 and the data were represented as mean \pm standard error (SEM). $P$ values were determined by a two way analysis of variance in order to compare the mean of each individual experimental group with the control unirradiated group. $P$ values $<0.05$ was statistically significant. 


\section{RESULTS}

\section{Blood analysis}

Irradiated group II showed a significant decrease in hemoglobin level $(10.43 \mathrm{~g} / \mathrm{dl})$ and hematocrit $(30.11 \%)$ when compared to those of control unirradiated group I $(15.03 \mathrm{~g} / \mathrm{dl}$ and $56.42 \%$ for $\mathrm{Hb}$ and $\mathrm{HCT}$, respectively). Also, a significant drop in the numbers of RBCs, WBCs and platelets was noticed after irradiation. Melatonin administration, in group IV, prior to irradiation protected animals from radiation hazardous effects which was obvious in all measured blood parameters (table 1). Where melatonin administrated irradiated group IV showed an elevation in Hb, HCT, numbers of RBCs, WBCs and platelets when compared to those of irradiated group II. No significant differences were observed in MCV, MCH and $\mathrm{MCHC}$ among all experimental groups.

\section{Biochemical analysis of spleen samples}

MDA level was significantly higher in untreated irradiated group II when compared to normal control group I. Melatonin administration prior to irradiation, in group IV, significantly reduced MDA level when compared to untreated irradiated group II (figure 1A). On the contrary, radiation exposure (group II) decreased the antioxidant enzymes (SOD, GSH and CAT) in a significant way when compared to control group I. However, the levels of SOD, GSH and CAT in melatonin administrated irradiated group IV were nearly similar to those of control group I (figure $1 \mathrm{~B}, \mathrm{C}$ and D). No significant change was observed between control group I and melatonin administrated unirradiated group III in all measured parameters.

\section{Apoptosis and necrosis in spleen}

Irradiation exposure, in group II, significantly reduced the number of viable cells in spleen with an elvetion in the number of apoptotic and necrotic cells (figure 2A). This can be explained by the elevated expression in the levels of apoptotic intracellular proteins (Bax, P53, caspase-3 and caspase-8) and the significant reduction in the expression of the anti-apoptotic protein Bcl-2. Melatonin administration prior to irradiation, in group IV, succeeded in protecting spleen cells from apoptosis. This was evident by the reduction in both of the apoptotic cells numbers (figure $2 \mathrm{~A}$ ) and the expression levels of apoptotic intracellular proteins (figure 2B); with the elevation in the expression level of Bcl-2.

\section{Cytokines results}

Figure 3 showed that radiation exposure significantly elevated levels of pro-inflammatory cytokines (TNF- $\alpha$, IFN- $\gamma$ and IL-1 $\beta$ ) in both plasma (figure $3 \mathrm{~A}$ ) and spleen samples (figure 3B) of irradiated group II when compared to their corresponding levels in unirradiated control group I. Melatonin administration before radiation exposure significantly reduced the cytokines levels in group IV when compared to group II. No significant differences could be detected in cytokines levels among control unirradiated groups I, melatonin administrated unirradiated group III and melatonin administrated irradiated group IV.

\section{Spontaneous and mitogen induced blastogenesis}

Irradiation exposure significantly increased the spontaneous blastogenesis of PBMC and spleen lymphocytes, which was obvious by the spontaneous ${ }^{3} \mathrm{H}-\mathrm{TdR}$ incorporation in cells' DNA of irradiated group II in comparison to control unirradiated group I (figures $4 \mathrm{~A}$ and $\mathrm{B}$ ). No significant differences were observed between control group I and melatonin administrated unirradiatted group III, either, in the spontaneous blastogenesis of PBMC or spleen lymphocytes (figures $4 \mathrm{~A}$ and $\mathrm{B}$ ). Melatonin administration before radiation exposure helped in the reduction of spontaneous blastogenesis in irradiated group IV when compared to irradiated group II. No significant differences were noticed in spleen lymphocytes response to PHA or Con A in different experimental groups (figure 4C). On the other hand, LPS-induced blastogenesis was significantly reduced after radiation exposure in group II. Group IV, administrated with melatonin before irradiation, showed LPS- induced blastogenesis nearly the same as control group I. 
Table 1. Complete blood picture of different experimental groups.

\begin{tabular}{|c|c|c|c|c|}
\hline Parameters & Group I & Group II & Group III & Group IV \\
\hline Hb (g/dl) & $15.03 \pm 0.46^{\mathrm{a}}$ & $10.43 \pm 0.22^{\mathrm{b}}$ & $15.61 \pm 1.20^{\mathrm{a}}$ & $14.55 \pm 1.56^{\mathrm{a}}$ \\
\hline HCT (\%) & $56.42 \pm 2.03^{\mathrm{a}}$ & $30.11 \pm 1.47^{\mathrm{c}}$ & $53.21 \pm 0.99^{\mathrm{a}}$ & $43.51 \pm 1.76^{\mathrm{b}}$ \\
\hline RBCs (10 $\mathbf{6} / \boldsymbol{\mathrm { L }})$ & $7.21 \pm 0.24^{\mathrm{a}}$ & $5.12 \pm 1.03^{\mathrm{b}}$ & $7.11 \pm 0.44^{\mathrm{a}}$ & $6.53 \pm 0.63^{\mathrm{a}}$ \\
\hline WBCs (10 $/ \mu \mathrm{L})$ & $8.01 \pm 0.12^{\mathrm{a}}$ & $4.61 \pm 0.93^{\mathrm{b}}$ & $8.93 \pm 0.77^{\mathrm{a}}$ & $7.55 \pm 0.87^{\mathrm{a}}$ \\
\hline PLTS (10 $\mathbf{3} / \boldsymbol{\mu L})$ & $495.22 \pm 65.01^{\mathrm{a}}$ & $254.78 \pm 21.44^{\mathrm{b}}$ & $512.01 \pm 44.56^{\mathrm{a}}$ & $453.47 \pm 12.35^{\mathrm{a}}$ \\
\hline MCV (fl) & $53.14 \pm 0.65^{\mathrm{a}}$ & $55.74 \pm 1.51^{\mathrm{a}}$ & $52.95 \pm 1.42^{\mathrm{a}}$ & $53.04 \pm 2.10^{\mathrm{a}}$ \\
\hline MCH (pg) & $19.35 \pm 0.72^{\mathrm{a}}$ & $18.33 \pm 0.22^{\mathrm{a}}$ & $18.43 \pm 0.30^{\mathrm{a}}$ & $18.00 \pm 1.99^{\mathrm{a}}$ \\
\hline MCHC (g/d) & $29.11 \pm 0.46^{\mathrm{a}}$ & $28.70 \pm 0.87^{\mathrm{a}}$ & $28.00 \pm 0.43^{\mathrm{a}}$ & $29.05 \pm 0.47^{\mathrm{a}}$ \\
\hline
\end{tabular}

Data were presented as mean \pm SEM. Means followed by the same letter within the same row were not significantly different $(P>0.05)$, whereas those marked with different ones were significantly different $(P<0.05)$ using analysis of variance [ANOVA]; Tukey test. Hb: Hemoglobin, HCT: Hematocrit, RBCs: Red blood cells, WBCs: White blood cells, PLT: Platelet, MCV: mean corpuscular volume, MCH: mean cell hemoglobin, MCHC: mean corpuscular hemoglobin concentration. Group I: control unirradiated rats, group II: irradiated rats, group III: 100 mg/Kg melatonin administrated unirradiated rats and group IV: $100 \mathrm{mg} / \mathrm{Kg}$ melatonin administrated irradiated rats.

Figure 1. Levels of A) malondialdehyde (MDA), B) superoxide dismutase (SOD), C) glutathione (GSH) and D) catalase (CAT) in spleen samples of different experimental groups. The untreated irradiated group II showed the highest level of MDA and the lowest levels of the antioxidant enzymes (SOD, CAT and GSH). Melatonin administration prior to irradiation, in group IV, protected the spleen cells from the hazardous effect of radiation. This was obvious in the reduction of MDA level and enhancement of the antioxidant enzymes activities in group IV when compared to untreated irradiated group II. Data were expressed as mean $\pm S E M$, a represents significance compared with the control group I, b represents significance compared with the untreated irradiated group II $(\mathrm{P}<0.05)$. Group I: control unirradiated rats, group II: untreated irradiated rats, group III: $100 \mathrm{mg} / \mathrm{kg}$ melatonin administrated unirradiated rats and group IV: $100 \mathrm{mg} / \mathrm{Kg}$ melatonin administrated irradiated rats.
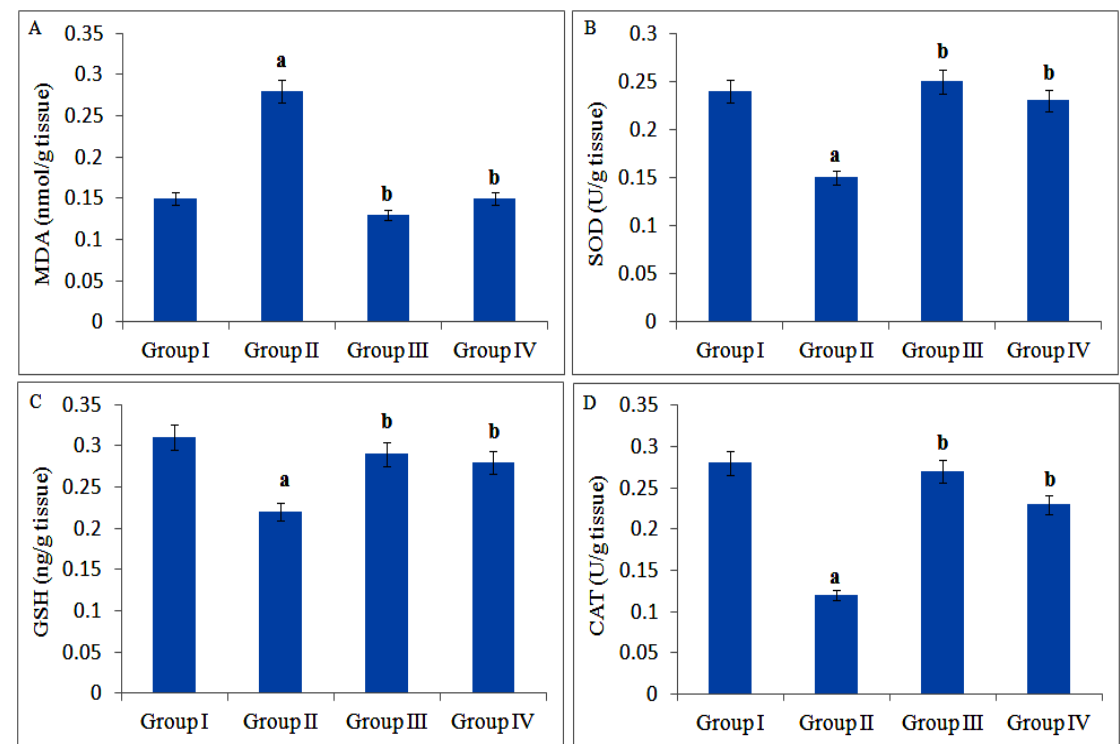

Figure 2. Changes in A) apoptosis level, B) apoptotic intracellular proteins (Bax, P53, caspase- 3 and caspase- 8 ) and anti-apoptotic protein $\mathrm{BCl}-2$ in spleen samples of different experimental groups. Radiation exposure decreased $\mathrm{Bcl}-2$ expression level and increased the apoptotic intracellular proteins expression levels that in turn increased the numbers of apoptotic cells. Melatonin administrated irradiated group IV showed decreased levels of all apoptotic proteins that

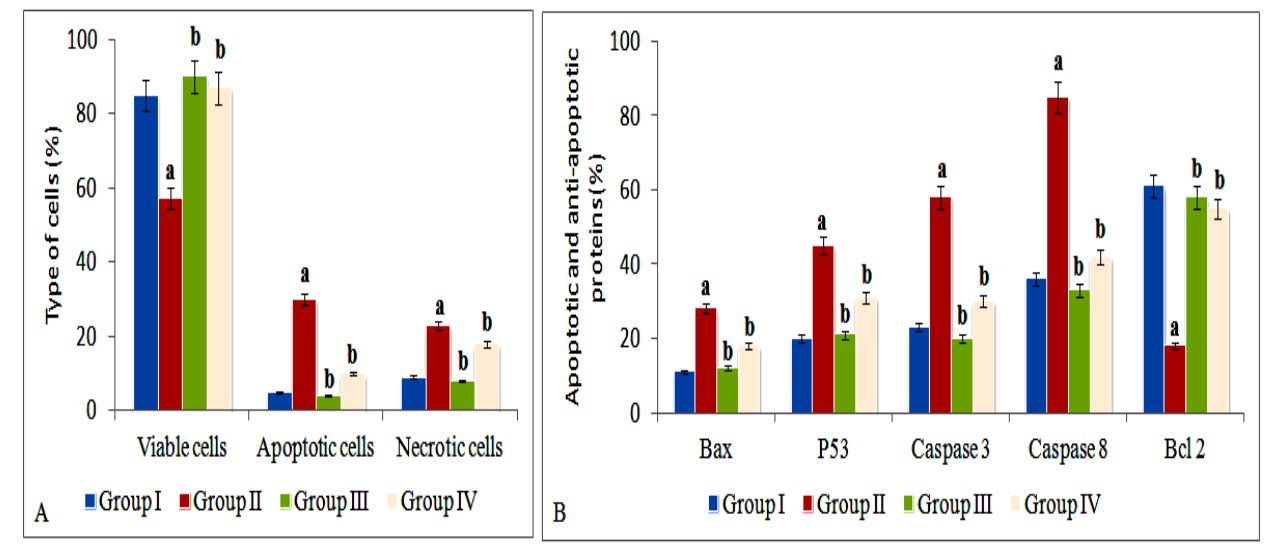

consequently decreased the numbers of apoptotic cells when compared to untreated irradiated group II. Data were expressed as mean $\pm S E M$, a represents significance compared with the control group I, b represents significance compared with the untreated irradiated group II $(\mathrm{P}<0.05)$. Group I: control unirradiated rats, group II: untreated irradiated rats, group III: $100 \mathrm{mg} / \mathrm{Kg}$ melatonin administrated unirradiated rats and group IV: $100 \mathrm{mg} / \mathrm{Kg}$ melatonin administrated irradiated rats. 

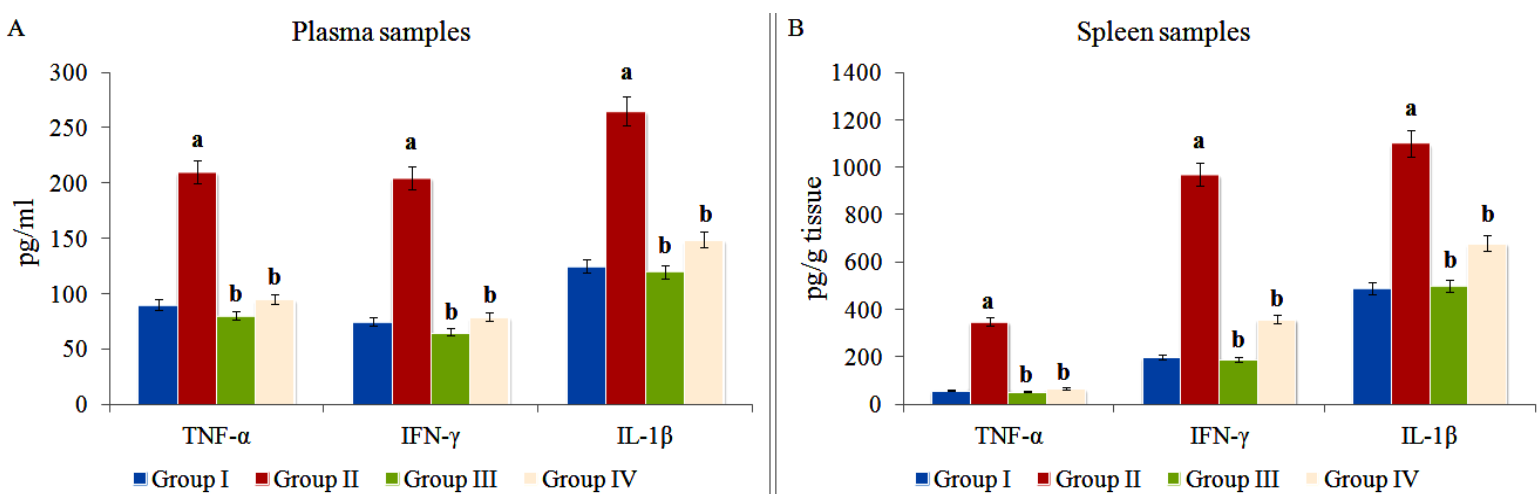

Figure 3. levels of tumor necrosis factor (TNF)- $\alpha$, interferon (IFN)- $-\gamma$ and interleukin (IL)-1 $\beta$ in A) plasma samples, B) spleen samples of different experimental groups. Radiation exposure elevated the levels of pro-inflammatory cytokines in untreated irradiated group II; on the other hand, melatonin administration reduced inflammation that followed irradiation in group IV. Data were expressed as mean $\pm S E M$, a represents significance compared with the control group I, b represents significance compared with the untreated irradiated group II ( $\mathrm{P}<0.05)$. Group I: control unirradiated rats, group II: untreated irradiated rats, group III: $100 \mathrm{mg} / \mathrm{Kg}$ melatonin administrated unirradiated rats and group IV: $100 \mathrm{mg} / \mathrm{Kg}$ melatonin administrated irradiated rats.

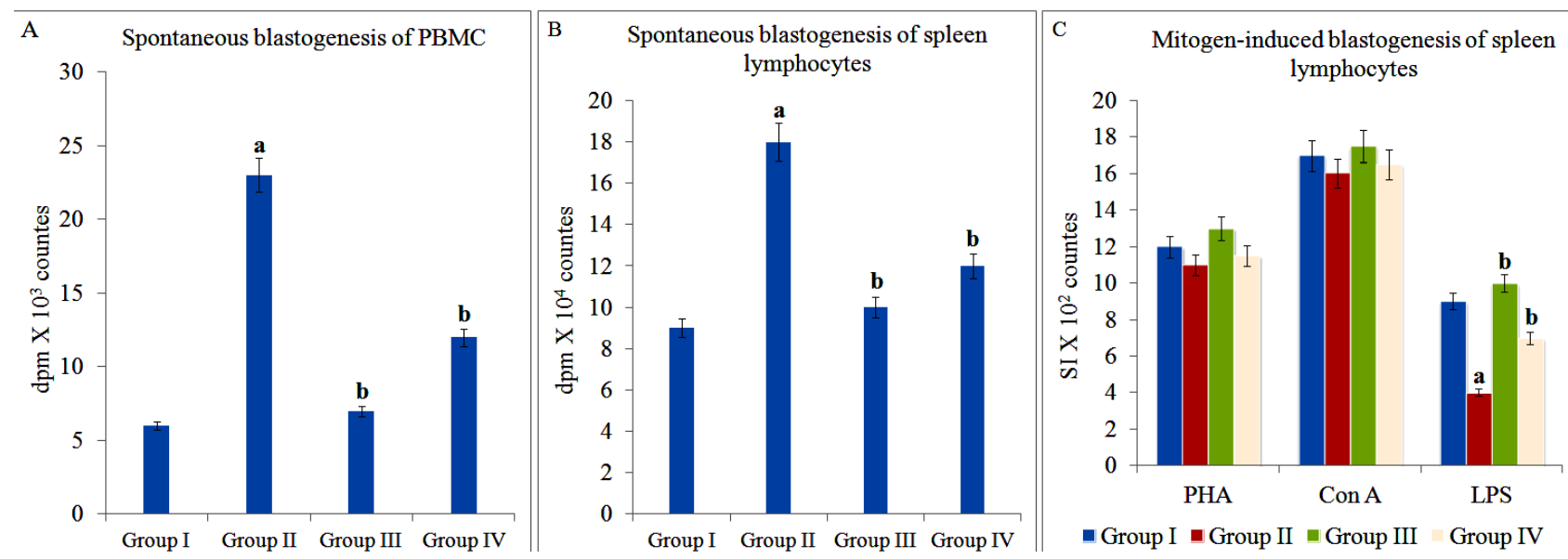

Figure 4. A) Spontaneous blastogenesis of PBMC, B) Spontaneous blastogenesis of spleen lymphocytes and C) mitogen-induced blastogenesis of spleen lymphocytes. Radiation exposure increased spontaneous blastogenesis in both PBMC and spleen lymphocytes; and decreased LPS- induced blastogenesis. Melatonin irradiated group IV showed spontaneous blastogenesis and

LPS-induced blastogenesis similar to those of control group I. Data were expressed as mean \pm SEM, a represents significance compared with the control group I, b represents significance compared with the untreated irradiated group II ( $<<0.05)$. Group I: control unirradiated rats, group II: untreated irradiated rats, group III: $100 \mathrm{mg} / \mathrm{Kg}$ melatonin administrated unirradiated rats and group IV: $100 \mathrm{mg} / \mathrm{Kg}$ melatonin administrated irradiated rats. PHA: phytohaemagglutinin, Con A: concanavalin A, LPS: lipopolysaccharides.

\section{DISCUSSION}

Ionizing radiation exposure has several hazardous effects such as inflammation, carcinogenesis, and apoptosis. Radiation exposure can occur through radiotherapy, experimentation, the work in nuclear stations, nuclear battlefields and nuclear accidents (34). Ionizing radiation encourages oxidative stress due to the increased production of free radicals that attack cell components leading to biochemical disruption and macromolecule alterations such as lipid peroxidation and DNA fragmentation (35). More than $50 \%$ of cancer patients undergo radiotherapy (36-37), which has a beneficial face in controlling tumors and in the same time may induce damages to bone marrow, liver, spleen and other organs (34). 
Therefore, several studies have been searching for radioprotective substances to protect normal tissues from the hazardous effects of radiation. The fact that free radicles formation is the main cause of cellular damage, that follows radiation exposure, makes free radicle scavengers and antioxidants the most anticipated excellent radioprotectors. Melatonin has been reported to be a direct free radical scavenger and an indirect antioxidant agent via its stimulation of the antioxidant enzymes activities (17-18). Melatonin, in vitro, inhibits lipid peroxidation and scavenged $\mathrm{OH}, \mathrm{H}_{2} \mathrm{O}_{2}$, and singlet oxygen $\left(_{2} \mathrm{O}_{2}-{ }^{-}{ }^{(13)}\right.$. It elevates the levels of GSH by activating the production of $\gamma$-glutamylcysteine synthase that blocks pro-oxidative enzymes lipoxygenase and nitric oxide synthase. It has been observed that melatonin reduces free radicals production by elevating the efficiency of electron transport chain that decreases electron leakage (38); and assists microsomal membranes in resisting oxidative stress (39). On the other hand, many studies have reported the radiosensitizer properties of melatonin. Melatonin elevated chromosomal aberrations in lymphocytes from patients with breast cancer (31). Also, pretreatment of breast cancer cells with melatonin prior to radiation exposure increased cells sensitization to radiation (32). This means that melatonin can act as a radiosensitizer agent on tumor cells and, in the same time, protect normal cells from the hazards that follow radiation exposure.

The present study examined the radioprotective effects of melatonin in whole body $\gamma$-radiated rats. Where, rats were injected with $100 \mathrm{mg} / \mathrm{kg}$ of melatonin before radiation exposure by 30 minutes. Whole body irradiation is a kind of radiotherapy that is commonly used for the treatment of some blood cancers before bone marrow transplantation. One of its complications is the drop in blood cell count. Our results showed that radiation exposure, in group II, led to a significant drop in hemoglobin level, hematocrit \% and in the numbers of RBCs, WBCs and platelets. On the other hand, melatonin administration protected rats from these side effects. Where all measured parameters of blood analysis, in melatonin administrated irradiated group, were nearly similar to those of control unirradiated group.

Irradiation causes water radiolysis inside the cells that in turn elevates the levels of free radicles and reduces its anti-oxidant system. This increase in free radicals levels leads to the overproduction of MDA which is the final products of polyunsaturated fatty acids peroxidation in the cells; and is considered a marker of oxidative stress and the antioxidant status of the cells. Levels of MDA have been shown to increase, after $\gamma$-radiation exposure, in brain ${ }^{40)}$, liver (41), serum (42), and lens ${ }^{(43)}$ of rats. In this study, spleen samples of irradiated group II showed a huge increase in MDA level that was aligned with the decrease in activities of the antioxidant enzymes SOD, GSH and CAT. This decrease was, mainly, due to the formation of antibodies against the cellular antioxidant enzymes that in turn decreased the enzymatic activity. Mohye El-Din et al. (44) showed that lipid peroxidation was an important marker of oxidative stress that followed radiation exposure. Zhang et al. (45) added that lipid peroxidation products led to apoptosis through the activation of caspases that in turn activated DNA degradation. In our study, a significant elevation in the numbers of necrotic and apoptotic cells in the spleen of whole body $\gamma$-irradiated rats was observed with a significant reduction in the number of the viable cells. This was concomitant with an increase in the expression of $\mathrm{p} 53$, Bax, caspase- 3 and caspase-8; and a decrease in the level of the anti-apoptotic protein Bcl-2. We observed that melatonin administration improved the anti-oxidant system in the spleen cells; which was obvious in the levels of MDA, SOD, GSH and CAT. It, also, down regulated the overexpression of pro-apoptotic proteins that followed irradiation and reduced the numbers of apoptotic and necrotic cells. Generally, Bax and Bcl-2 are the most common genes involved in radiation induced-apoptosis (46). Where the up regulation of Bax and down regulation of Bcl-2 activated casapase-3 leading to the release of cytochrome $\mathrm{C}$ from mitochondria. In our study, the reduction in apoptosis can be linked to melatonin administration because melatonin up regulated

Int. J. Radiat. Res., Vol. 19 No. 4, October 2021 
Bcl-2 gene and down regulated Bax gene that in turn reduced Bax/Bcl-2 ratio. This was in agreement with the previous work of Shirazi et al. (47) who reported that melatonin blocked apoptosis in irradiated spinal cord by decreasing Bax gene expression and increasing Bcl-2 gene expression. And, Sharma et al. (48-49) showed that melatonin protected squirrel's lymphoid organs from the toxicity of X-rays exposure and reduced apoptosis by blocking the activity of caspase- 3 .

In addition to free radicals production, inflammatory process is another mechanism of indirect toxicity post-irradiation (50). Kryston et al. (51) reported that irradiation led to the induction of ROS and RNS that disrupt the normal redox balance inside the cells leading to severe inflammatory processes. Farid et al. (52-53) reported that many pro-inflammatory cytokines were released shortly after irradiation such as IL $-1 \beta$, IL- 6 and TNF- $\alpha$ which were of particular importance in radiation toxicity pathophysiology. Farid et al. (54) added that cytokines are low molecular weight proteins that have a stimulating or inhibiting effect on immune system cells' proliferation, differentiation and function. This was in agreement with our results, as TNF- $\alpha$, IFN- $\gamma$ and IL-1 $\beta$ levels in plasma and spleen samples of irradiated group were highly elevated than normal control group I. This elevation in pro-inflammatory cytokines was down regulated in melatonin administrated irradiated group. The observed vigorous increase in pro-inflammatory cytokines, following radiation exposure, was mainly due to the elevated necrosis/apoptosis ratio that initiated NF- $\mathrm{kB} /$ NLRP3 inflammasome pathway. This pathway was responsible for the production of many inflammatory mediators following irradiation. It can be conclude that the increased secretion of pro-inflammatory cytokines and apoptosis was a mutual process. As, the combined effects of increased secretion of IFN- $\gamma$, IL- $1 \beta$ and TNF- $\alpha$ in spleen of irradiated group II significantly elevated necrosis/apoptosis ratio, and vice versa. On the other hand, melatonin administration inhibited NF- $\kappa B / N L R P 3$ inflammasome pathway leading to the reduction of inflammation, cytokines secretion (55-56), and in turn necrosis/apoptosis ratio. Melatonin has been reported to reduce radiation-induced inflammation in the lung, heart and brain (57-58).

In this study, spontaneous blastogenesis was performed on PBMC and spleen lymphocytes to measure the degree of cell proliferation after exposure to whole body $\gamma$-radiation. Based on this assay, radiation exposure significantly increased the incorporation of 3H-TdR into DNA of both PBMC and spleen lymphocytes. This elevation in spontaneous blastogenesis was associated with a significant drop in the count of WBCs. This can be explained by the fact that radiation exposure decreased cell count and enhanced DNA synthesis. Also, mitogen-induced blastogenesis was used to measure the change in spleen lymphocytes responsiveness after radiation exposure. The results showed that LPS -induced blastogenesis was greatly reduced after radiation exposure in group II; while no changes were detected with PHA or Con A. This can be explained by: 1- radiation greatly reduced the number of $B$ lymphocytes than that of T lymphocytes (59), 2- LPS was a non-specific stimulator of B lymphocytes and 3- PHA and Con A were $\mathrm{T}$ lymphocyte mitogens ${ }^{600)}$. On the other hand, melatonin administrated irradiated group IV showed no significant differences with control group I either in the spontaneous or LPS-induced blastogenesis results.

In conclusion, the study proofed that beside the radiosensitizer effect of melatonin on cancer cells (31-32); it has a radioprotective effect on normal cells. Therefore, melatonin can be recommended to be used as a radioprotector before radiation exposure in radiotherapy, experimentation.... etc due to: 1 - it acted as a free radicle scavenger and an anti-oxidant agent in different cells and organs, 2- it up regulated the activities of SOD, GSH and CAT, 3-it reduced lipid peroxidation process as indicated by the decreased level of MDA, 4- it prevented the harmful effects of radiation on all blood parameters, 5- it displayed an anti-apoptotic effect by the down regulation of pro-apoptotic proteins (p53, Bax, caspase-3 and caspase-8) and up regulation of anti-apoptotic protein Bcl-2, 6- it maintained an anti-inflammatory effect that decreases the pro-inflammatory 
cytokines (IL-1 $\beta$, IFN- $\gamma$ and TNF- $\alpha$ ) and 7 - it protected PBMC and spleen B lymphocytes and stabilized their proliferation.

\section{Conflicts of interest: Declared none.}

\section{REFERENCES}

1. Baskar R, Lee KA, Yeo R, Yeoh KW (2012) Cancer and radiation therapy: current advances and future directions. Int $J$ Med Sci, 9:193-199.

2. Barnett GC, West $C M$, Dunning $A M$, Elliott RM, Coles $C E$, Pharoah PD, Burnet NG (2009) Normal tissue reactions to radiotherapy: towards tailoring treatment dose by genotype. Nat Rev Cancer, 9:134-142.

3. Mozdarani H (2012) Biological complexities in radiation carcinogenesis and cancer radiotherapy: impact of new biological paradigms. Genes (Basel), 3(1): 90-114.

4. Manda K, Glasow A, Paape D, Hildebrandt G (2012) Effects of ionizing radiation on the immune system with special emphasis on the interaction of dendritic and T cells. Front Oncol, 2: 102.

5. Yahyapour R, Amini $P$, Rezapour S, Cheki M, Rezaeyan A, Farhood B, Shabeeb D, Musa AE, Fallah H, Najafi M (2018) Radiation-induced infammation and autoimmune diseases. Mil Med Res, 5(1): 9.

6. Yahyapour R, Motevaseli E, Rezaeyan A, Abdollahi H, Farhood B, Cheki M, Rezapoor S, Shabeeb D, Musa AE, Najafi $M$, Villa V (2018) Reduction-oxidation (redox) system in radiation-induced normal tissue injury: molecular mechanisms and implications in radiation therapeutics. Clin Transl Oncol, 20(8): 975-988.

7. Castellani P, Balza E, Rubartelli A (2014) Infammation, DAMPs, tumor development, and progression: a vicious circle orchestrated by redox signaling. Antioxid Redox Signal, 20(7): 1086-1097.

8. Rubin LG and Schaffner W (2014) Clincial practice. Care of the splenic patient. N Eng J Med, 371: 349-356.

9. Cihan YB (2018) Which is the best? Palliative Radiation Therapy to Spleen or Splenectomy. J Radiol Oncol, 2: 003008.

10. Zhao L, Liu L, Guo B, Zhu B (2015) Regulation of adaptive immune responses by guiding cell movements in the spleen. Front Microbiol, 6: 645.

11. Vijayalaxmi V, Meltz ML, Reiter RJ, Herman TS, Kumar SK (1999) Melatonin and protection from whole-body irradiation: survival studies in mice. Mutation Research, 425(1): 21-27.

12. Karbownik M and Reiter RJ (2000) Antioxidative effects of melatonin in protection against cellular damage caused by ionizing radiation (44547). Experimental Biology and Medicine, 225(1): 9-22.

13. Vijayalaxmi, Reiter RJ, Tan DX, Herman TS, Thomas CR Jr (2004) Melatonin as a radioprotective agent: a review. Int J Radiat Oncol Biol Phys, 59(3): 639-653.
14. Reiter RJ, Tan DX, Cabrera J, D'Arpa D, Sainz RM, Mayo JC, Ramos S (1999) The Oxidant/Antioxidant network: role of melatonin. Biol Signals Recept, 8(1-2): 56-63.

15. Kennaway DJ and Voultsios A (1998) Circadian rhythm of free melatonin in human plasma. J Clin Endocrinol Metab, 83(3): 1013-1015.

16. Yu H, Dickson EJ, Jung S-R, Koh D-S, Hille B (2016) High membrane permeability for melatonin. J Gen Physiol, 147 (1): 63-76.

17. Rodriguez C, Mayo JC, Sainz RM, Antolín I, Herrera F, Martín V, Reiter RJ (2004) Regulation of antioxidant enzymes: a signifcant role for melatonin. J Pineal Res, 36 (1): 1-9.

18. Shirazi A, Ghobadi G, Ghazi-Khansari M (2007) A radiobiological review on melatonin: a novel radioprotector. J Pineal Res, 48(4): 263-272.

19. Sharma S and Haldar C (2006) Melatonin prevents X-ray irradiation induced oxidative damage in peripheral blood and spleen of the seasonally breeding rodent, Funambulus pennanti during reproductively active phase. Int I Radiat Biol, 82(6): 411-419.

20. Siu AW, Reiter RJ, To CH (1999) Pineal indoleamines and vitamin $\mathrm{E}$ reduce nitric oxide-induced lipid peroxidation in rat retinal homogenates. J Pineal Res, 27(2): 122-128.

21. Sainz RM, Mayo JC, Uría H, Kotler M, Antolín I, Rodriguez C, Menendez-Pelaez A (1995) The pineal neurohormone melatonin prevents in vivo and in vitro apoptosis in thymocytes. J Pineal Res, 19(4): 178-188.

22. Maestroni GJ, Covacci V, Conti A (1994) Hematopoietic rescue via T-cell-dependent, endogenous granulocyte macrophage colony-stimulating factor induced by the pineal neurohormone melatonin in tumor-bearing mice. Cancer Res, 54(9): 2429-2432.

23. Cagnoli CM, Atabay C, Kharlamova E, Manev H (1995) Melatonin protects neurons from singlet oxygen-induced apoptosis. J Pineal Res, 18(4): 222-226.

24. Farhood B, Goradel NH, Mortezaee K, Khanlarkhani $\mathrm{N}$, Salehi E, Nashtaei MS, Mirtavoos-Mahyari H, Motevaseli E, Shabeeb D, Musa AE (2019) Melatonin as an adjuvant in radiotherapy for radioprotection and radiosensitization. Clin Transl Oncol, 21(3): 268-279.

25. Vijayalaxmi, Reiter RJ, Sewerynek E, Poeggeler B, Leal BZ, Meltz ML (1995) Marked reduction in radiation induced micronuclei in human blood lymphocytes pretreated with melatonin. Radiat Res, 143: 102-106.

26. Anwar MM, Mahfouz HA, Sayed AS (1998) Potential protective effects of melatonin on bone marrow of rats exposed to cytotoxic drugs. Comp Biochem Physiol, 119: 493 $-591$.

27. Canyilmaz E, Uslu GH, Bahat Z, Kandaz M, Mungan S, Haciislamoglu E, Mentese A, Yoney A (2016) Comparison of the effects of melatonin and genistein on radiationinduced nephrotoxicity: Results of an experimental study. Biomed Rep, 4(1): 45-50.

28. Kamal El-Dein EM, Anees LM (2020) Ameliorative role of melatonin against cypermethrin or gamma irradiation induced testicular damage in male rat. Int J Radiat Res, 18 (4): 765-776.

Int. J. Radiat. Res., Vol. 19 No. 4, October 2021 
29. Seker U, Aktas A, Nergiz Y, Zincircioglu SB, Ketani MA (2020) Investigation of the protective effects of melatonin, amifostine (WR-2721), and N-acetylcysteine on radiotherapy-induced uterine tissue injury in rats. Int J Radiat Res, 18(4): 791-798.

30. Najafi M, Motevaseli E, Shirazi A, Geraily Gh, Rezaeyan A, Norouzi F, Rezapoor S, Abdollahi H (2018) Mechanisms of inflammatory responses to radiation and normal tissues toxicity: clinical implications. Int J Radiat Biol, 94(4): 335356.

31. Samei E, Mozdarani H, Samiei F, Javadi GR (2020) Radiosensitizing effects of melatonin on radiation induced chromosomal aberration in G2-lymphocytes of breast cancer patient. Int J Radiat Res, 18(4): 657-662.

32. Alonso-Gonzalez C, Gonzalez A, Martinez-Campa C, GomezArozamena J, Cos S (2015) Melatonin sensitizes human breast cancer cells to ionizing radiation by downregulating proteins involved in double-strand DNA break repair. J Pineal Res, 58: 189-197.

33. Farid A, Hesham M, El-Dewak M, Amin A (2020) The hidden hazardous effects of stevia and sucralose consumption in male and female albino mice in comparison to sucrose. Saudi Pharmaceutical Journal, 28(10): 1290-1300.

34. Nair CK, Parida DK, Nomura T (2001) Radioprotectors in radiotherapy. J Radiat Res, 42: 21-37.

35. Fuchs-Tarlovsky V (2013) Role of antioxidants in cancer therapy. Nutri, 29: 15-21.

36. Bentzen SM (2006) Preventing or reducing late side effects of radiation therapy: radiobiology meets molecular pathology. Nat Rev Cancer, 6(9): 702-713.

37. Buonanno M, de Toledo SM, Pain D, Azzam El (2011) Longterm consequence of radiation-induced bystander effects depend on radiation quality and dose and correlate with oxidative stress. Radiat Res, 175(4): 405-415.

38. Reiter RJ1, Tan DX, Manchester LC, Qi W (2001) Biochemical reactivity of melatonin with reactive oxygen and nitrogen species: a review of the evidence. Cell Biochem Biophys, 34(2): 237-256.

39. Karbownik M, Garcia JJ, Lewiński A, Reiter RJ (2001) Carcinogen-induced, free radical-mediated reduction in microsomal membrane fluidity: reversal by indole-3propionic acid. J Bioenerg Biomembr, 33(1): 73-78.

40. Bernard ME, Kim H, Rwigema JC, Epperly MW, Kelley EE, Murdoch GH, Dixon T, Wang H, Greenberger JS (2011) Role of the esophageal vagus neural pathway in ionizing irradiation-induced seizures in nitric oxide synthase-1 homologous recombinant negative NOS1-/- mice. In-Vivo, 25(6): 861-869.

41. Kalpana KB, Devipriya $N$, Srinivasan $M$, Vishwanathan $P$, Thayalan K, Menon VP (2011) Evaluating the radioprotective effect of hesperidin in the liver of Swiss albino mice. Eur J Pharmacol, 658(2-3): 206-212.

42. Hu Y, Guo DH, Liu P, Cao JJ, Wang YP, Yin J, Zhu Y, Rahman $K$ (2011) Bioactive components from the tea polyphenols influence on endogenous antioxidant defense system and modulate inflammatory cytokines after total-body irradiation in mice. Phytomedicine, 18(11): 970-975.

43. Karslioglu I, Ertekin MV, Koçer I, Taysi S, Sezen O, Gepdire-

Int. J. Radiat. Res., Vol. 19 No. 4, October 2021 men A, Balci E (2004) Protective role of intramuscularly administered vitamin $E$ on the levels of lipid peroxidation and the activities of antioxidant enzymes in the lens of rats made cataractous with gamma-irradiation. Eur J Ophthalmol, 14(6): 478-485.

44. Mohye El-Din AA, Abdelrazzak AB, Ahmed MT, El-missiry MA (2017) Radiation induced bystander effects in the spleen of cranially-irradiated rats. $\mathrm{Br} J$ Radiol, 90: 20170278.

45. Zhang W, He Q, Chan LL, Zhou F, El Naghy M, Tompson EB, Ansari NH (2001) Involvement of caspases in 4hydroxyalkenal-induced apoptosis in human leukemic cells. Free Radic Biol Med, 30: 699-706.

46. Cui YF, Ding YQ, Zhang Y, Xu H, Jin W, Liu XL, Dong B, Mao JP, Mao BZ (2005) Apoptotic characteristics of spleen lymphocyte in mice irradiated by lethal dose and its relationship to the expression of $\mathrm{Bax}$ and $\mathrm{Bcl}-\mathrm{XL}$ proteins. Zhongguo Wei Zhong Bing Ji Jiu Yi Xue, 17(2): 109-112.

47. Shirazi A, Haddadi G, Minaee B, Sepehrizadeh Z, Mahdavi S, Jaberi E, Haddadi M (2010) Evaluation of melatonin for modulation of apoptosisrelated genes in irradiated cervical spinal cord. Int J Low Radiation, 7(6):436-445.

48. Sharma S, Haldar C, Chaube SK, Laxmi T, Singh SS (2010) Long-term melatonin administration attenuates low-LET $\gamma$ radiation- induced lymphatic tissue injury during the reproductively active and inactive phases of Indian palm squirrels (Funambulus pennanti). Br J Radiol, 83(986): 137151.

49. Sharma S1, Haldar C, Chaube SK (2008) Effect of exogenous melatonin on X-ray induced cellular toxicity in lymphatic tissue of Indian tropical male squirrel, Funambulus pennant. Int J Radiat Biol, 84(5): 363-374.

50. Hall S, Rudrawar S, Zunk M, Bernaitis N, Arora D, McDermott CM, Anoopkumar-Dukie S (2016) Protection against radiotherapy-induced toxicity. Antioxidants J, 5: 22.

51. Kryston TB, Georgiev AB, Pissis P, Georgakilas AG (2011) Role of oxidative stress and DNA damage in human carcinogenesis. Mutat Res Fund Mol Mech Mut, 711: 193-201.

52. Farid A, Kamel D, Montaser SA, Ahmed MM, El Amir M, El Amir A (2020) Assessment of antioxidant, immune enhancement, and antimutagenic efficacy of fennel seed extracts in irradiated human blood cultures. Journal of Radiation Research and Applied Sciences, 13(1): 260-266.

53. Farid A, Kamel D, Montaser SA, Ahmed MM, El Amir M, El Amir A (2020) Synergetic role of senna and fennel extracts as antioxidant, anti-inflammatory and a-mutagenic agents in irradiated human blood lymphocyte cultures. Journal of Radiation Research and Applied Sciences, 13(1): 191-199.

54. Farid A, Tawfik A, Elsioufy B, Safwat G (2020) Narrow Band Ultraviolet B Therapy Deactivates Th1/Th17 Pathway and Activates Th2 Cytokines Secretion in Egyptian Psoriatic Arthritis Patients. Journal of Radiation Research and Applied Sciences, 13(1): 356-361.

55. Ortiz F, Acuna-Castroviejo D, Doerrier C, Dayoub JC, Lopez LC, Venegas C, García JA, López A, Volt H, Luna-Sánchez M (2015) Melatonin blunts the mitochondrial/NLRP3 connection and protects against radiation-induced oral mucositis. 
J Pineal Res, 58(1): 34-49.

56. Fernández-Gil $B$, Moneim AE, Ortiz $F$, Shen $Y Q$, SotoMercado V, Mendivil-Perez M, Guerra-Librero A, AcuñaCastroviejo D, Molina-Navarro MM, García-Verdugo JM (2017) Melatonin protects rats from radiotherapy-induced small intestine toxicity. PLoS One, 12(4): e0174474.

57. Aricigil M, Dundar MA, Yucel A, Eryilmaz MA, Aktan M, Alan MA, Fındık S, Kılınç I (2017) Melatonin prevents possible radiotherapy-induced thyroid injury. Int J Radiat Biol, 93(12): 1350-1356.

58. Najaf M, Shirazi A, Motevaseli E, Geraily G, Norouzi F,
Heidari M, Rezapoor S (2017) The melatonin immunomodulatory actions in radiotherapy. Biophys Rev, 9(2): 139148.

59. Pecaut MJ, Nelson GA, Gridley DS (2001) Dose and doserate effects of whole body $\gamma$-irradiation: I. lymphocytes and lymphoid organs. In-Vivo, 15: 195-208.

60. Gridley DS, Pecaut MJ, Miller GM, Moyers MF, Nelson GA (2001) Dose and dose rate effects of whole-body gammairradiation: II. Hematological variables and cytokines. InVivo, 15(3): 209-16. 